\title{
Eficiência de métodos de melhoramento para teor de fibra e produtividade de grãos em progênies de feijoeiro comum
}

\author{
Adélia Cristina Fernandes Silva ( $\left.{ }^{(*}\right)$; Patrícia Guimarães Santos Melo (1); Leonardo Cunha Melo $\left({ }^{2}\right)$ \\ Priscila Zaczuk Bassinello $\left({ }^{2}\right)$; Helton Santos Pereira $\left({ }^{2}\right)$ \\ (') Universidade Federal de Goiás (UFG), Programa de Pós-graduação em Agronomia, Campus Samambaia, Rod. Goiânia/Nova \\ Veneza, km 0, 74001-970 Goiânia (GO), Brasil. \\ (2) Embrapa Arroz e Feijão (Cnpaf), Rod. GO-462, km 12, zona rural, 75375-000 Santo Antônio de Goiás (GO), Brasil. \\ (*) Autora correspondente: adeliacrist@yahoo.com.br
}

Recebido: 17/abr./2013; Aceito: 10/nov./2013

\begin{abstract}
Resumo
O objetivo deste estudo foi comparar métodos de melhoramento quanto à variabilidade genética e à eficiência na obtenção de progênies superiores para teor de fibra bruta e produtividade de grãos em feijoeiro comum. As progênies foram obtidas do cruzamento, em 2003, entre as linhagens carioca CNFC 7812 e CNFC 7829. A população segregante foi conduzida por bulk, bulk dentro de $F_{2}$ e SSD até geração $F_{7}$. Em 2008 foram amostradas aleatoriamente 64 progênies de cada método para avaliação em Goiás e Paraná. Foram obtidas as estimativas dos componentes de variância, parâmetros genéticos e fenotípicos, média e índices de geração de progênies superiores. As progênies obtidas pelos métodos de bulk e SSD apresentaram diferenças significativas para produtividade e teor de fibra bruta e maior variância genética. O bulk dentro de $F_{2}$ apresentou os maiores índices de geração de progênies superiores e maiores médias para os dois caracteres, sendo recomendado para os programas de melhoramento de feijoeiro comum.
\end{abstract}

Palavras-chave: Phaseolus vulgaris, interação genótipo × ambiente, SSD, bulk, bulk dentro de famílias.

\section{Efficiency of breeding methods for crude fiber content and grain yield in common bean progenies}

\begin{abstract}
The objective was to compare breeding methods referring to genetic variability and the efficiency in obtaining superior progenies for crude fiber content and grain yield in common bean plants. The progenies were obtained by crossing Carioca in bredlines CNFC 7812 and CNFC 7829 in 2003. The segregating population was conducted by bulk, bulk within $F_{2}$ and SSD until the $F_{7}$ generation. In 2008, 64 progenies were chosen randomly according to each breeding method for evaluation in Goiás and Paraná States. The estimates of variance component, genetic and phenotypic parameters, means and indexes of superior progenie generations were obtained during this study. The progenies obtained by bulk and SSD methods presented significant differences for grain yield and crude fiber content along with larger genetic variance. The bulk within $F_{2}$ presented higher indexes of superior progenies generation and larger averages for both characters as compared to the other methods, being recommended for breeding programs of common beans.
\end{abstract}

Key words: Phaseolus vulgaris, genotype by environment, SSD, bulk, bulk within $\mathrm{F}_{2}$.

\section{INTRODUÇÃO}

O feijāo comum (Phaseolus vulgaris) é um alimento tradicionalmente presente na dieta dos brasileiros. A qualidade tecnológica dos grãos é de grande importância, uma vez que o feijão é consumido por todas as classes sociais, sendo para as de menor poder aquisitivo a principal fonte de proteínas, minerais, vitaminas e fibras (BASsinello, 2009).

A qualidade nutricional vem despertando grande interesse no mercado de grãos (Mittelmann et al.,
2003). Dentre os nutrientes destacam-se as fibras, que são componentes importantes da dieta humana por exercerem efeitos benéficos na saúde, auxiliando na prevenção de doenças do sistema digestivo e do coração, além de contribuirem para a redução do colesterol, no controle glicêmico e na prevenção de câncer de cólon (Hughes, 1991; Moore et al., 1998; Vanderhoof, 1998).

O conhecimento da variabilidade genética em genótipos brasileiros de feijoeiro comum é muito importante, uma vez que as informaçôes disponíveis são poucas e o consumo 
desse grão é grande (LoNDERo et al., 2005). Essas informaçóes podem auxiliar os programas de melhoramento genético que buscam desenvolver cultivares de feijoeiro comum mais produtivos associados às características de qualidade.

Teores de fibra bruta variando de 3,82\% a 5,67\% foram encontrados por ANTUNEs et al. (1995) ao analisarem quatro cultivares de feijoeiro comum. LONDERo et al. (2008b) encontraram teor médio de fibra bruta em grãos do grupo preto variando de $3,42 \%$ a $4,30 \%$. Ribeiro et al. (2005) analisaram 220 genótipos de feijoeiro comum, sendo 83 do grupo comercial preto e 137 de cor, verificando teores de fibra bruta variando de 3,40\% a 5,17\% em feijôes do grupo preto e de $3,31 \%$ a $5,57 \%$ em feijóes de cor.

$\mathrm{O}$ aumento da qualidade nutricional do feijáo quanto ao teor de fibra possibilitará o acesso a uma alimentação rica nesse componente, uma vez que o feijão é um dos principais alimentos de mais de 300 milhóes de pessoas no mundo, principalmente nos países em desenvolvimento de regiôes tropicais e subtropicais (Melo et al., 2011). Assim, é importante que seja avaliada a eficiência relativa dos métodos de melhoramento genético para esse caráter, uma vez que a variabilidade é função da diversidade genética dos genitores e, também, dos métodos de condução das populaçôes segregantes (Castanheira e Santos, 2004). As comparaçóes entre métodos de condução de populaçôes segregantes em feijoeiro comum são poucas e visam, principalmente, a produtividade de grãos (RANALLI et al.,1996; RAposo et al., 2000; Urrea e Singh, 1994).

RANALLI et al. (1996), utilizando duas populaçóes segregantes, avaliaram a eficiência do método SSD (Single Seed Descent) e da seleção precoce em plantas $\mathrm{F}_{2}$, concluindo que o método SSD apresentou desempenho ligeiramente superior à seleção precoce, mas não descartaram a utilização desse método associado ao SSD. RAPOso et al. (2000) concluíram que não houve diferenças significativas entre os métodos, para produtividade de grãos, na obtenção de progênies superiores. Utilizaram como critérios o desempenho médio das progênies, o ganho esperado com diferentes intensidades de seleçáo e o número de progênies provenientes de cada método com desempenho superior a um determinado padrão. Porém, considerando as estimativas dos parâmetros genéticos e fenotípicos, juntamente com a facilidade e flexibilidade de condução, os métodos bulk e SSD foram os mais vantajosos.

Alguns programas de melhoramento genético do feijoeiro comum têm direcionado seus trabalhos para o desenvolvimento de cultivares produtivos, agregando outras características de interesse, dentre elas, a fibra bruta nos grãos. Para que essas metas sejam alcançadas deve-se ter disponível variabilidade genética suficiente para o caráter e estratégias eficientes para detectar diferenças entre os genótipos elite. $\mathrm{O}$ objetivo deste estudo foi comparar métodos de melhoramento quanto à variabilidade genética e eficiência na obtençáo de progênies superiores para teor de fibra bruta e produtividade de grãos em feijoeiro comum.

\section{MATERIAL E MÉTODOS}

Foi realizado, em 2003, o cruzamento entre as linhagens com grãos tipo carioca CNFC 7812 e CNFC 7829, desenvolvidas pelo programa de melhoramento da Embrapa Arroz e Feijão, Santo Antônio de Goiás, GO. A população obtida foi dividida e conduzida por três métodos de melhoramento, a partir da geração $\mathrm{F}_{2}$ : bulk (1.000 plantas por geração até $\mathrm{F}_{5}$, com seleção aleatória de 100 plantas nessa geração), bulk dentro de famílias $F_{2}\left(100\right.$ progênies por geração até $\left.F_{5}\right)$ e SSD - Single Seed Descent (100 sementes por geração até $\mathrm{F}_{5}$ ). A condução dessas populaçóes segregantes foi realizada segundo descrito por Ramalho et al. (2001) e conforme, também, adotado por Ramalho et al. (2012). A partir da geração $\mathrm{F}_{5}$ foram amostradas aleatoriamente 64 progênies de cada método, sendo multiplicadas na geração $\mathrm{F}_{6}$.

A avaliação das 192 progênies (64/método) foi realizada na geração $\mathrm{F}_{7}$, juntamente com quatro cultivares comerciais (BRS Estilo, BRS Pontal, BRS Cometa e BRS Horizonte). Os ambientes de avaliação foram os municípios: Santo Antônio de Goiás (GO), localizado a $16^{\circ} 28^{\prime} 00^{\prime \prime} \mathrm{S}, 49^{\circ} 17^{\prime} 00^{\prime \prime} \mathrm{O}$, altitude de $823 \mathrm{~m}$, na safra do inverno de 2008; e Ponta Grossa (PR), localizado a $25^{\circ} 05^{\prime} 42^{\prime \prime} \mathrm{S}, 50^{\circ} 09^{\prime} 43^{\prime \prime O}$, altitude de $969 \mathrm{~m}$, na safra das águas de 2008. O delineamento foi um látice triplo $14 \times 14$, com parcela de duas linhas de quatro metros de comprimento com 15 sementes por metro. Foi obtida a produtividade em g parcela ${ }^{-1}$, posteriormente convertida em kg ha ${ }^{-1}$.

As avaliaçốes do teor de fibra bruta foram realizadas com amostras das três repetições de campo provenientes dos dois ensaios. O método utilizado foi o da digestão ácidobase descrito pela AOAC (1997), com modificações. Nessa metodologia, a quantificação da fibra bruta é realizada por meio de diluiçóes ácidas e básicas em recipientes denominados cadinho de Gooch, o que dificulta a quantificação em um número grande de amostras. As modificaçôes realizadas neste trabalho consistiram em realizar a extração da fibra bruta no equipamento denominado determinador de fibras da Tecnal $^{\oplus}$, modelo TE-149, que originalmente determina fibra detergente neutro (FDN) e fibra detergente ácido (FDA), possibilitando a extração em um número maior de amostras, o que o torna um método mais rápido e menos oneroso.

Foram realizadas as análises individuais e conjunta de variância para o teor de fibra bruta e para a produtividade de grãos das progênies nos dois locais. A partir da análise conjunta de variância, desdobraram-se os graus de liberdade das progênies e progênies $\times$ ambiente para cada método, obtendo-se as respectivas estimativas de parâmetros genéticos e fenotípicos, segundo Vencovsky e Barriga (1992). Estimaram-se os índices de geração de progênies superiores, representados pelo número de progênies superiores à média dos genitores, número de progênies superiores à média do melhor genitor e o número de progênies superiores entre as 20 melhores. 
Estimou-se a correlação de Pearson entre o teor de fibra e a produtividade de grãos das progênies para cada método, segundo o modelo de Steel e Torrie (1980). Para as dez progênies mais produtivas dos três métodos, calculou-se o ganho de seleção conforme CRUz (2005).

\section{RESULTADOS E DISCUSSÃO}

Os resultados mostraram que houve diferença significativa entre as progênies para teor de fibra bruta e produtividade de gráos, indicando que existe variabilidade entre elas (Tabela 1). $\mathrm{O} \mathrm{CV}_{\mathrm{e}}$ para produtividade de grãos e teor de fibra bruta, nos dois ambientes, está dentro do que normalmente se encontra para esses caracteres (Londero et al., 2008b; Pereira et al., 2009; Ribeiro et al., 2005). Os valores médios encontrados nesses dois últimos trabalhos, para fibra bruta, foram de $8,19 \%$ e $9,26 \%$, respectivamente.

As progênies conduzidas pelo método do bulk dentro de $\mathrm{F}_{2}$ apresentaram diferenças significativas $(\mathrm{p} \leq 0,05)$ apenas para produtividade de grãos (Tabela 1). No método do bulk houve diferenças significativas para produtividade de grãos e teor de fibra bruta $(\mathrm{p} \leq 0,01)$ e no método SSD as diferenças também foram significativas $(\mathrm{p} \leq 0,01)$ para produtividade $\mathrm{e}$ $(\mathrm{p} \leq 0,05)$ para teor de fibra.

Foi observada a presença da interação progênies $x$ ambientes, indicando o comportamento diferenciado das progênies nos dois ambientes, para ambos os caracteres (Tabela 1). A interaçáo genótipos $\times$ ambientes para teor de fibra em feijáo também foi constatada por LONDERO et al. (2008a). Para produtividade de grãos, a presença da interação tem sido constatada por vários autores (BERTOLDO et al., 2009; Carbonell et al., 2004; Melo et al., 2007; Oliveira et al., 2006; Pereira et al., 2009; 2010). A estimativa da variância da interação foi bastante pronunciada, representando 69\% da variância genética para o caráter produtividade de grãos e $55 \%$ para o caráter teor de fibra bruta (Tabela 2). Não houve interação entre as progênies de cada método com ambiente, para nenhum dos dois caracteres. As testemunhas interagiram com ambientes apenas para o teor de fibra.

Normalmente, espera-se que os métodos do bulk e SSD proporcionem maior variabilidade entre as progênies, pois a variabilidade disponível que é liberada a partir da geração $\mathrm{F}_{7}$ é 1,97 da variância genética aditiva $\left(\sigma_{\mathrm{A}}^{2}\right)$ (RAmalho et al., 2012). No bulk/ $\mathrm{F}_{2}$, a variabilidade entre as progênies, independentemente da geração em que foi efetuada a seleção, é a mesma da existente entre plantas $F_{2}$, ou seja, $1 \sigma^{2}{ }_{A}$ (Ramalho et al., 2012). Embora, normalmente esses resultados sejam esperados, durante a conduçáo de uma população segregante vários fatores podem afetar a eficiência desses métodos. Entre esses fatores destacam-se a atuação da seleção natural, as perdas decorrentes do processo de amostragem, além dos efeitos da interação de genótipos com ambientes, que neste trabalho não foram

Tabela 1. Resumo da análise de variância conjunta para os caracteres produtividade de grãos e teor de fibra bruta das progênies $\mathrm{F}_{7}$ de feijoeiro comum obtidas por três métodos de condução de populações, 2008

\begin{tabular}{|c|c|c|c|c|c|}
\hline \multirow{2}{*}{ FV } & \multirow{2}{*}{ GL } & \multicolumn{2}{|c|}{ Quadrado médio } & \multicolumn{2}{|c|}{ Quadrado médio } \\
\hline & & Produtividade de grãos & p-valor & Teor de fibra bruta & p-valor \\
\hline Ambiente $(\mathrm{A})$ & 1 & $94.856 .549,00$ & $6,72 \mathrm{E}-87$ & 16,049 & $2,13 E-14$ \\
\hline Métodos (M) & 2 & $4.181 .425,50$ & $1,96 \mathrm{E}-10$ & 1,1375 & $1,36 \mathrm{E}-02$ \\
\hline Rep/A & 4 & $1.207 .745,80$ & 2,87E-05 & 1,167 & $1,52 \mathrm{E}-03$ \\
\hline Bloco/Rep/A & 78 & $438.335,96$ & $1,62 \mathrm{E}-09$ & 0,356445 & 2,79E-02 \\
\hline Genótipos (G) & 195 & $358.493,05$ & $1,20 \mathrm{E}-10$ & 0,400976 & 6,33E-05 \\
\hline Progênies (P) & 191 & $359.772,31$ & $1,28 \mathrm{E}-10$ & 0,3656 & $1,58 \mathrm{E}-03$ \\
\hline Prog/Bulk $\mathrm{F}_{2: 7}$ & 63 & $250.703,66$ & $3,03 E-02$ & 0,307565 & $1,83 \mathrm{E}-01$ \\
\hline Prog/Bulk & 63 & $355.731,69$ & $2,75 \mathrm{E}-05$ & 0,396189 & $8,76 \mathrm{E}-03$ \\
\hline Prog/SSD & 63 & $354.251,59$ & $3,08 \mathrm{E}-05$ & 0,368978 & $2,55 \mathrm{E}-02$ \\
\hline Entre métodos & 2 & $4.691 .433,60$ & $1,41 \mathrm{E}-11$ & 1,123695 & $1,44 \mathrm{E}-02$ \\
\hline Testemunhas (T) & 3 & $178.033,89$ & 4,00E-01 & 0,6979 & $4,78 \mathrm{E}-02$ \\
\hline $\mathrm{P} \times \mathrm{T}$ & 1 & $655.532,08$ & $5,75 \mathrm{E}-02$ & 6,2671 & $1,32 \mathrm{E}-06$ \\
\hline$M \times A$ & 2 & $124.759,80$ & $5,03 E-01$ & 0,01414 & $9,48 \mathrm{E}-01$ \\
\hline$G \times A$ & 195 & $304.482,23$ & $9,55 \mathrm{E}-07$ & 0,342086 & $9,09 \mathrm{E}-03$ \\
\hline$P \times A$ & 191 & $200.170,92$ & $1,86 \mathrm{E}-01$ & 0,2148 & $9,56 \mathrm{E}-01$ \\
\hline Bulk $F_{2: 7} \times A$ & 63 & $162.803,88$ & $6,96 \mathrm{E}-01$ & 0,212204 & $8,58 \mathrm{E}-01$ \\
\hline Bulk $\times A$ & 63 & $224.879,90$ & $1,06 \mathrm{E}-01$ & 0,211996 & $8,59 \mathrm{E}-01$ \\
\hline$S S D \times A$ & 63 & $216.731,92$ & $1,49 \mathrm{E}-01$ & 0,2268 & $7,68 \mathrm{E}-01$ \\
\hline Contraste & 2 & $77.228,31$ & $6,53 \mathrm{E}-01$ & 0,0069 & $9,74 \mathrm{E}-01$ \\
\hline$T \times A$ & 3 & $58.505,24$ & $8,09 \mathrm{E}-01$ & 1,074334 & 6,90E-03 \\
\hline$P: T \times A$ & 1 & $20.965 .874,00$ & $4,43 E-25$ & 22,4569 & $3,02 \mathrm{E}-19$ \\
\hline Erro efetivo & 698 & $181.154,75$ & & 0,263246 & \\
\hline Total & 1.175 & & & & \\
\hline
\end{tabular}


Tabela 2. Estimativas de parâmetros genéticos e fenotípicos para os caracteres produtividade de grãos e teor de fibra bruta de progênies $\mathrm{F}_{7}$ de feijoeiro comum obtidas por diferentes métodos de melhoramento e avaliadas em Santo Antônio de Goiás, GO, e Ponta Grossa, PR, no ano agrícola de 2008

\begin{tabular}{|c|c|c|c|c|c|c|c|c|}
\hline \multirow{2}{*}{ Estimativas } & \multicolumn{2}{|c|}{ Todos os métodos } & \multicolumn{2}{|c|}{ Bulk } & \multicolumn{2}{|c|}{ Bulk $F_{2: 7}$} & \multicolumn{2}{|c|}{ SSD } \\
\hline & $\mathbf{P G}^{(1)}$ & Fibra & $P G^{(1)}$ & Fibra & $\mathbf{P G}^{(1)}$ & Fibra & $\mathbf{P G}^{(1)}$ & Fibra \\
\hline$\hat{\sigma}_{g}^{2}$ & $29.769,6$ & 0,022 & $29.096,2$ & 0,022 & $11.591,5$ & 0,007 & $28.849,5$ & 0,0176 \\
\hline$\hat{\sigma}_{f}^{2}$ & $59.748,8$ & 0,066 & $59.288,6$ & 0,066 & $41.783,9$ & 0,051 & $59.041,9$ & 0,0614 \\
\hline$\hat{\sigma}_{f x a}^{2}$ & $20.554,6$ & 0,012 & 7,287 & 0 & 0 & 0 & 5,929 & 0 \\
\hline$h_{m}^{2}(\%)$ & 49,8 & 34,0 & 49,0 & 33,5 & 27,7 & 14,0 & 49,0 & 28,7 \\
\hline$C V_{e}(\%)$ & 22,4 & 11,38 & 12,7 & 5,73 & 10,0 & 4,95 & 13,2 & 5,53 \\
\hline GS\% & 12,09 & 3,15 & 10,18 & 2,89 & 4,09 & 0,94 & 8,77 & 2,29 \\
\hline Média geral & $1.929,7$ & 4,52 & $1.909,90$ & 4,48 & $2.046,0^{(2)}$ & $4,57^{(3)}$ & $1.843,39$ & 4,47 \\
\hline$r$ & \multicolumn{2}{|c|}{$-0,06^{\mathrm{ns}}$} & \multicolumn{2}{|c|}{$-0,19^{\text {ns }}$} & \multicolumn{2}{|c|}{$-0,009^{\text {ns }}$} & \multicolumn{2}{|c|}{$-0,17^{\text {ns }}$} \\
\hline
\end{tabular}

detectados em nenhum dos métodos. A produtividade de grãos pode ser afetada por esses três fatores, já o teor de fibra, normalmente, é afetado somente pelas variaçôes de amostragem e interaçôes, pois não está relacionado com vantagens adaptativas, pelas quais atua a seleçáo natural, conforme mostraram os trabalhos de Allard (1988); Corte et al. (2002) e Pirola et al. (2002).

Neste trabalho observou-se que a variância genética entre as progênies foi maior nos métodos de bulk e SSD (Tabela 2). Coerentemente, observou-se maior herdabilidade nesses métodos, comparados ao método do bulk dentro de famílias - bulk $\left(\mathrm{F}_{2: 7}\right)$. Porém observou-se que a média de produtividade de gráos $\left(2.046 \mathrm{~kg} \mathrm{ha}^{-1}\right)$ e teor de fibra bruta $(4,57 \%)$ foram maiores para as progênies conduzidas pelo método do bulk dentro de famílias.

Os teores médios de fibra bruta encontrados nos três métodos foram 4,47\% (SSD), 4,48\% (bulk) e 4,57\% (bulk dentro de famílias) (Tabela 2). Tais valores são próximos aos encontrados por Antunes et al. (1995), que foram de $3,82 \%$ a $5,67 \%$. Segundo esses autores, o cultivar Carioca apresentou o menor teor médio de fibra $(3,82 \%)$. LONDERo et al. (2008b) encontraram teor médio de fibra bruta em grãos do grupo preto variando de 3,42\% a 4,30\%.

O ganho de seleção das dez melhores progênies, nos três métodos avaliados, mostrou valores positivos, representando o aumento das médias para as duas características comparativamente às médias das 64 progênies (Tabela 2). Para a produtividade de grãos, o método bulk apresentou o maior ganho de seleção, que foi de $9,56 \%$, seguido pelo método SSD, ganho de $8,05 \%$, e pelo método bulk dentro de famílias, ganho de 3,39\%. Para o teor de fibra bruta, o método bulk também obteve o maior ganho de seleção (2,85\%), seguido pelo SSD (2,25\%) e pelo bulk dentro de famílias $(0,94 \%)$, sendo esse pouco expressivo.

LONDERo et al. (2006) encontraram ganhos semelhantes $(2,04 \%)$ com a seleção de famílias $\mathrm{F}_{2}$ da combinação entre as cultivares de feijoeiro comum BRS Valente e Varre-Sai para fibra alimentar total. Ganhos com a seleção para produtividade de grãos foram calculados em diversos trabalhos (Pereira et al., 2004; 2008; Silva et al., 2009) e os valores obtidos são bastante variáveis (de 2,4\% a 79,5\%).

Verificou-se que não houve correlação significativa $(\mathrm{p} \leq 0,05)$ entre os dois caracteres avaliados (Tabela 2). Em trabalho similar, porém com fibra alimentar (solúvel, insolúvel e total), LONDERo et al. (2006) também não encontraram associação entre as diferentes fraçoóes da fibra alimentar e a produtividade de grãos, ressaltando que a associação dessas duas características em um genótipo será um desafio para os melhoristas.

Com relação ao teor de fibra, o método do bulk dentro de famílias apresentou 25 progênies superiores ao melhor genitor (CNFC 7812-4,64\%) e 39 (61\%) acima da média dos genitores (Tabela 3). No método SSD foram identificadas 19 progênies superiores ao melhor genitor e 29 (45,3\%) progênies superiores às médias dos genitores. $\mathrm{O}$ método do bulk apresentou 15 progênies superiores ao melhor genitor e $27(42,2 \%)$ progênies superiores às médias dos genitores. Embora, nos três métodos, houvesse variabilidade entre as progênies indicando que é possível selecionar as superiores, é preciso considerar, também, a média do caráter, para garantir o sucesso com a seleção.

Constatou-se que nenhum método apresentou progênies com média superior à do melhor genitor, que foi $2.597,4 \mathrm{~kg} \mathrm{ha}^{-1}$. No bulk dentro de famílias foram encontradas seis progênies com médias acima da média dos genitores $\left(2.315,9 \mathrm{~kg} \mathrm{ha}^{-1}\right)$. No método do bulk foram encontradas quatro progênies acima desse valor e no SSD não foi encontrada nenhuma. Assim, nessas comparaçóes em que foram consideradas as médias das progênies mais uma vez o método de bulk dentro de famílias destacou-se.

Foram selecionadas as 20 melhores progênies, para ambos os caracteres, considerando-se as 192 progênies, a fim de identificar qual método originou as melhores progênies (Tabela 3). Para teor de fibra bruta, a predominância de 
Tabela 3. Índices de geração de progênies superiores representados pelo número de progênies superiores à média dos genitores, número de progênies superiores à média do melhor genitor e número de progênies superiores entre as 20 melhores em método para os caracteres teor de fibra bruta e produtividade de grãos em feijoeiro comum

\begin{tabular}{|c|c|c|c|c|c|c|}
\hline \multirow{2}{*}{ Método } & \multicolumn{3}{|c|}{ Teor de fibra bruta } & \multicolumn{3}{|c|}{ Produtividade de grãos } \\
\hline & (1) & (2) & (3) & (1) & (2) & (3) \\
\hline Bulk $F_{2: 7}$ & $39(61,0 \%)$ & 25 & 8 & $6(9,0 \%)$ & 0 & 12 \\
\hline SSD & $29(45,3 \%)$ & 19 & 7 & $4(6,25 \%)$ & 0 & 7 \\
\hline Bulk & 27 (42,2\%) & 15 & 5 & $0(0 \%)$ & 0 & 1 \\
\hline
\end{tabular}

progênies superiores foi do método bulk dentro de $\mathrm{F}_{2}(40 \%)$ e do método bulk (35\%), seguidos pelo SSD (25\%). Para produtividade de grãos, $60 \%$ das melhores progênies foram originadas pelo método do bulk dentro de $\mathrm{F}_{2}, 35 \%$ pelo método do bulk e apenas $5 \%$ por SSD.

De modo geral, o método do bulk dentro de famílias $\mathrm{F}_{2}$ foi o mais eficiente na obtenção de progênies com maiores teores de fibra e produtividade, com resultados mais pronunciados para produtividade de grãos. Esses resultados reforçam a importância de associar a média e a variância do caráter visando alcançar genótipos superiores.

Do exposto, e levando-se em conta todos os critérios, o melhor método de condução de populações segregantes, considerando o número de progênies superiores obtidas e as médias para os caracteres produtividade de grãos e teor de fibra bruta, foi o bulk dentro de famílias. Essa tendência foi mais acentuada para a produtividade de grãos. A variabilidade entre as progênies nesse método foi pequena, refletindo em menores ganhos com a seleção, portanto não se deve esperar avanços nesses caracteres nas geraçôes seguintes.

O método do bulk, mesmo obtendo maior variabilidade, gerou baixo número de progênies superiores à média geral dos genitores para os dois caracteres. Porém, apresentou a possibilidade de ganhos com a seleção, o que pode ser favorável em geraçôes posteriores. O método SSD foi o que apresentou menos progênies superiores sendo, portanto, $\mathrm{o}$ menos indicado.

\section{CONCLUSÃO}

O método do bulk dentro de famílias foi o mais eficiente na geração de progênies superiores de feijoeiro comum do grupo carioca para teor de fibra bruta e produtividade de grãos. O cruzamento CNFC $7812 \times$ CNFC 7829 apresenta potencial genético para geração de progênies superiores para teor de fibra bruta e produtividade de grãos.

\section{REFERÊNCIAS}

ALLARD, R.W. Genetic changes associated with the evolution of adaptedness in cultivated plants and their wild progenitors. Journal of Heredity, v.79, p.225-238, 1988. PMid:3166481.
ANTUNES, P.L.; BILHALVA, A.B.; ELIAS, M.C.; SOARES, G.J.D. Valor Nutricional de Feijão (Phaseolus vulgaris, L.), Cultivares Rico 23, Carioca, Piratâ-1 e Rosinha-G2. Revista Brasileira de Agrociência, v.1, p.12-18, 1995.

ASSOCIATION OF OFFICIAL ANALYTICAL CHEMISTS AOAC. Methods of analysis of AOAC International. Washington: AOAC, 1997. 200 p.

BASSINELLO, P.Z. Qualidade nutricional, funcional e tecnológica do feijão. In: KLUTHCOUSKI, J.; STONE, L.F.; AIDAR, H. (Ed.). Fundamentos para uma agricultura sustentável, com ênfase na cultura do feijoeiro. Embrapa Arroz e Feijão, Santo Antônio de Goiás, 2009. p.385-424.

BERTOLDO, J.G.; COIMBRA, J.L.M.; NODARI, R.O.; GUIDOLIN, A.F.; HEMP, S.; BARILI, L.D.; VALE, N.M.; ROZZETO, D.S. Stratification of the state of Santa Catarina in macro-environments for bean cultivation. Crop Breeding and Applied Biotechnology, v.9, p.335-343, 2009.

CARBONELL, S.A.M.; AZEVEDO FILHO, J.A.; DIAS, L.A.S.; GARCIA, A.A.F, MORAIS, L.K. Common bean cultivars and lines interactions with environments. Scientia Agricola, v.61, p.169177, 2004. http://dx.doi.org/10.1590/S0103-90162004000200008

CASTANHEIRA, A.L.M.; SANTOS, J.B. RAPD marker assessment of self-pollinated inbreeding methods for common bean segregant populations. Crop Breeding and Applied Biotechnology, v.4, p.16, 2004.

CORTE, H.C.; RAMALHO, M.A.P.; GONÇALVES, F.M.A.; ABREU, A.F.B. Natural selection for grain yield in dry bean populations bred by the bulk method. Euphytica, v.123, p.387-393, 2002. http:// dx.doi.org/10.1023/A:1015065815131

CRUZ, C.D. Princípios de Genética Quantitativa. Viçosa: UFV, 2005. 394p.

HUGHES, J.S. Potential contribution of dry bean dietary fiber to health. Food Technology, v.45, p.122-126, 1991.

LONDERO, P.M.G.; RIBEIRO, N.D.; RODRIGUES, J.A.; POERSCH, N.L.; TRENTIN, M. Genetic variability for dietary fiber content in common bean populations. Crop Breeding and Applied Biotechnology, v.5, p.86-90, 2005.

LONDERO, P.M.G.; RIBEIRO, N.D.; CARGNELUTTI FILHO, A.; RODRIGUES, J.A.; ANTUNES, I.F. Herdabilidade dos teores de fibra alimentar e rendimento de grãos em populaçôes de feijoeiro. Pesquisa Agropecuária Brasileira, v.41, p.51-58, 2006. http://dx.doi. org/10.1590/S0100-204X2006000100008 
LONDERO, P.M.G.; RIBEIRO, N.D.; POERSCH, N.L.; ANTUNES, I.F.; NÖRNBERG, J.L. Análise de fraçôes de fibra alimentar em cultivares de feijão cultivadas em dois ambientes. Ciência Rural, v.7, p.2033-2036, 2008a. http://dx.doi.org/10.1590/S010384782008000700037

LONDERO, P.M.G.; RIBEIRO, N.D.; CARGNELUTTI, A.F. Teores de fibra e rendimento de grãos em populaçóes de feijão. Ciência e Agrotecnologia, v.32, p.167-163, 2008b. http://dx.doi.org/10.1590/ S1413-70542008000100024

MELO, L.C.; MELO, P.G.S.; FARIA, L.C.; DIAZ, J.L.C.; DEL PELOSO, M.J.; RAVA, C.A.; COSTA, J.G.C. Interação com ambientes e estabilidade de genótipos de feijoeiro comum na Região Centro-Sul do Brasil. Pesquisa Agropecuária Brasileira, v.42, p.715-723, 2007. http://dx.doi.org/10.1590/S0100-204X2007000500015

MELO, L.C.; DEL PELOSO, M.J.; SARTORATO, A.; PEREIRA, P.A.A. Pré-melhoramento do feijáo-comum. In: LOPES, M.A.; FÁVERO, A.P.; FERREIRA, M.A.J.F.; FALEIRO, F.G.; FOLLE, S.M.; GUIMARÁES, E.P. (Ed.). Pré-melhoramento de plantas: estado da arte e experiências de sucesso. Brasília: Embrapa Informação Tecnológica: Embrapa Recursos Genéticos e Biotecnologia; Planaltina: Embrapa Cerrados, 2011. p.441-485.

MITTELMANN, A.; MIRANDA FILHO, J.B.; LIMA, G.J.M.M. Potential of the Esa23b Maize Population for Protein and Oil Content Improvement. Scientia Agricola, v.60, p.319-327, 2003. http://dx.doi. org/10.1590/S0103-90162003000200017

MOORE, M.A.; PARK, C.B.; TSUDA, H. Soluble and insoluble fiber influences on cancer development. Critical Reviews in Oncology/ Hematology, v.27, p.229-242, 1998. http://dx.doi.org/10.1016/ S1040-8428(98)00006-7

OLIVEIRA, G.V.; CARNEIRO, P.C.S.; CARNEIRO, J.E.S.; CRUZ, C.D. Adaptabilidade e estabilidade de linhagens de feijão comum em Minas Gerais. Pesquisa Agropecuária Brasileira, v.41, p.257-265, 2006. http://dx.doi.org/10.1590/S0100-204X2006000200010

PIROLA, L.H.; RAMALHO, M.A.P.; CARNEIRO, J.E.S.; ABREU, A.F.B. Natural selection ande family $\mathrm{x}$ location interaction in the commom (dry) bean planta. Genetics and Molecular Biology, v. 25, p.343-347, 2002. http://dx.doi.org/10.1590/S141547572002000300016

PEREIRA, H.S.; SANTOS, J.B.; ABREU, A.F.B. Linhagens de feijoeiro com resistência à antracnose selecionadas quanto a características agronômicas desejáveis. Pesquisa Agropecuária Brasileira, v.39, p.209215, 2004. http://dx.doi.org/10.1590/S0100-204X2004000300002

PEREIRA, H.S.; SANTOS, J.B.; SOUZA, T.P.; LIMA, I.A. Seleção fenotípica e assistida por marcadores moleculares de famílias de feijoeiro-comum com alta produtividade. Pesquisa Agropecuária Brasileira, v.43, p.1551-1558, 2008. http://dx.doi.org/10.1590/ S0100-204X2008001100014
PEREIRA, H.S.; MELO, L.C.; FARIA, L.C.; DEL PELOSO, M.J.; COSTA, J.G.C.; RAVA, C.A.; WENDLAND, A. Adaptabilidade e estabilidade de genótipos de feijoeiro-comum com grăos tipo carioca na Região Central do Brasil. Pesquisa Agropecuária Brasileira, v.44, p.29-37, 2009. http://dx.doi.org/10.1590/S0100-204X2009000100005

PEREIRA, H.S.; MELO, L.C.; FARIA, L.C.; DEL PELOSO, M.J.; WENDLAND, A. Estratificação ambiental na avaliação de genótipos de feijoeiro-comum tipo Carioca em Goiás e no Distrito Federal. Pesquisa Agropecuária Brasileira, v.45, p.554-562, 2010. http:// dx.doi.org/10.1590/S0100-204X2010000600004

RAMALHO, M.A.P.; ABREU, A.F.B.; SANTOS, J.B. Melhoramento de espécies autógamas. In: NASS, L.L.; VALOIS, A.C.C.; MELO, I.S.; VALADARES-INGLIS, M.C. (Ed.). Recursos Genéticos e Melhoramento de Plantas. Rondonópolis: Fundação MT, 2001. p.201-230.

RAMALHO, M.A.P.; ABREU, A.F.B.; SANTOS, J.B.; NUNES, J.A.R. Aplicaçóes da genética quantitativa no melhoramento de plantas autógamas. Lavras: Editora UFLA, 2012. 522p.

RANALLI, P.; RUARO, G.; RE, P.; FAETI, V. Comparison of early generation yield testing and a single seed descent procedure in two bean (Phaseolus vulgares L.) crosses. Journal of Genetics \& Breeding, v. 50, p.103-108, 1996.

RAPOSO, F.V.; RAMALHO, M.A.P.; ABREU, A.F.B. Comparação de métodos de condução de população segregantes na cultura do feijoeiro. Pesquisa Agropecuária Brasileira, v.35, p.1991-1997, 2000. http://dx.doi.org/10.1590/S0100-204X2000001000010

RIBEIRO, N.D.; LONDERO, P.M.G.; HOFFMANN, L.J.; POERSCH, N.L.; CARGNELUTTI, A.F. Dissimilaridade genética para proteína e fibra em grãos de feijão dos grupos preto e de cor. Revista Brasileira de Agrociência, v.11, p.167-173, 2005.

SILVA, C.A.; ABREU, A.F.B.; RAMALHO, M.A.P. Associação entre arquitetura de planta e produtividade de grãos em progênies de feijoeiro de porte ereto e prostrado. Pesquisa Agropecuária Brasileira, v.44, p.1647-1652, 2009. http://dx.doi.org/10.1590/ S0100-204X2009001200013

STEEL, R.G.D.; TORRIE, J.H. Principles and procedures of statistics: a biometrical approach. New York: McGraw-Hill, 1980. 631p.

URREA, C.A.; SINGH, S.P. Comparison of mass, F2-derived family, and single-seed-descent selection method in an interracial population of common bean. Canadian Journal of Plant Science, v.74, p.461464, 1994. http://dx.doi.org/10.4141/cjps94-085

VANDERHOOF, J.A. Immunonutrition: the role of carbohydrates. Nutrition Research, v.14, p.595-598, 1998.

VENCOVSKY, R.; BARRIGA, P. Genética biométrica no melhoramento. Ribeirão Preto: Sociedade Brasileira de Genética, 1992. 496 p. 